\title{
ARCHAEOLOGICAL RADIOCARBON DATES FOR STUDYING THE POPULATION HISTORY IN EASTERN FENNOSCANDIA
}

\author{
M Oinonen $^{1} \cdot$ P Pesonen $^{2} \cdot$ M Tallavaara $^{3}$ \\ ABSTRACT. In this work, archaeological radiocarbon data gathered from eastern Fennoscandia have been scrutinized to dis- \\ cuss their suitability for studies of population history. The temporal distribution of the archaeological ${ }^{14} \mathrm{C}$ dates has been ana- \\ lyzed against possible research priorities and sample material deterioration. An outstanding "Stone Age" maximum has been \\ observed in practically all the displayed temporal date distributions. The pattern remains the same throughout the history of \\ ${ }^{14} \mathrm{C}$ dating in Finland. Due to sample material differences, equal taphonomic corrections based on ${ }^{14} \mathrm{C}$-dated volcanic deposits \\ cannot account for all the sample degradation effects; therefore, material-dependent correction procedures are suggested.
}

\section{INTRODUCTION}

There is an increasing interest worldwide to investigate prehistoric population history based on distributions of radiocarbon dates (e.g. Gamble et al. 2005; Fiedel and Kuzmin 2007; Shennan and Edinborough 2007). It has been noted, however, that positively curvilinear frequency distributions sometimes observed in archaeological contexts can also be observed in paleontological and geological contexts due to time-dependent destructive processes (Surovell and Brantingham 2007). This fact demands special attention to whether the observed distribution pattern indeed reflects the true demographic signal.

The dates-as-data approach has been applied in this work on this question in the area of eastern Fennoscandia (see also Tallavaara et al. 2010). Archaeological ${ }^{14} \mathrm{C}$ data gathered from the eastern Fennoscandian context has been scrutinized to discuss the suitability of the data for studies of population history. Specifically, the factors affecting the shape of the date distribution have been elaborated to use the data as a basis for archaeological interpretations related to population history (Tallavaara et al. 2010). The obtained results will eventually support the spatiotemporal studies of the population history of the eastern Fennoscandia combining archaeology and genetics (Onkamo et al. 2008).

The paper is organized as follows. First, biases potentially influencing the ${ }^{14} \mathrm{C}$ dates distributions within eastern Fennoscandia are briefly discussed. Methods are presented to study the potentially most apparent biasing factors in detail. The yielding ${ }^{14} \mathrm{C}$ date distributions are presented and discussed within the framework established. Date distributions are scrutinized against the most evident sources of biases: possible research priorities and deterioration of sample materials. The approach of Surovell et al. (2009) is applied to attempt taphonomic correction for the most common sample materials. Finally, an estimation for the own-age effect of wood and charcoal samples is presented on the observed distribution maximum with respect to the own-age-free data.

\section{BACKGROUND}

Studying past population levels with ${ }^{14} \mathrm{C}$ dates is founded on the basic assumption that the date frequency correlates positively with the number of past inhabitants. Those inhabitants left datable material remains that are assumed to be dated randomly in relation to their age. This is not straightforwardly plausible, since it is likely that varying research emphases might play a role. The selection

\footnotetext{
${ }^{1}$ Finnish Museum of Natural History, Dating Laboratory, University of Helsinki, Finland. Corresponding author. Email: markku.j.oinonen@helsinki.fi.

${ }^{2}$ National Board of Antiquities, Department of Archaeology, Finland.

${ }^{3}$ Institute for Cultural Research, Department of Archaeology, University of Helsinki, Finland.
}

(C) 2010 by the Arizona Board of Regents on behalf of the University of Arizona Proceedings of the 20th International Radiocarbon Conference, edited by A J T Jull RADIOCARBON, Vol 52, Nr 2-3, 2010, p 393-407 
mechanism leading to a ${ }^{14} \mathrm{C}$ date is a result of a complicated chain of events that starts from the observation of an archaeological site. It is followed by excavation, an identification of datable material, and, eventually, sample selection. All these phases may result in a bias that shows up in the temporal distribution. Furthermore, one has to assume that the date frequencies are free from other types of biases such as taphonomic effects (Surovell and Brantingham 2007) and other natural processes. However, since sample degradation is a well-known feature of wood and bone, in particular, the assumption deserves a closer look. Sample degradation operates behind all sample selection mechanisms and limits the possible material types to choose from for ${ }^{14} \mathrm{C}$ dating.

Most archaeological surveys in Finland are carried out by the cultural heritage authorities (National Board of Antiquities) without any scientific interest or focus on certain periods. The same applies to rescue excavations at sites determined by contemporary land use rather than by scientific questions. Thus, such surveys and excavations should not yield ${ }^{14} \mathrm{C}$ dates purposefully concentrated on certain archaeological phases. On the other hand, their potential effect on geographical biases should be kept in mind: the number of rescue excavations may correlate positively with the density of construction sites, for instance.

Time-dependent destructive processes can also have an effect on age distributions, as Surovell and Brantingham (2007) note. Organic samples are less likely to survive over time after deposition. Particularly, the soil of eastern Fennoscandia is known to be naturally acidic due to the absence of neutralizing minerals such as limestone. The acidic soil deteriorates bone material (Mays 1998 and references therein) and makes it unattainable for future archaeological study. On the other hand, cremation at $>600^{\circ} \mathrm{C}$ is known to recrystallize the inorganic carbonates imbedded in the bone structure (Lanting et al. 2001). Recrystallized inorganic carbonates are expected to survive better in the hostile eastern Fennoscandian soil compared to organic bone collagen. Wood and plant samples in general are subjected to decomposition due to different abiotic (moisture, temperature, $\mathrm{pH}$ ) and biotic factors (microbial activity). Although the eastern Fennoscandian latitudes provide a less hostile environment for organic matter compared to central Europe thanks to colder temperatures, the estimated mass loss for pine is up to 5\% per 3 yr in typical forest soils (Jurgensen et al. 2004).

A charred material has a better resistance to these environmental challenges. Charcoal, due to varying uses of fire, is commonly found in archaeological sites, and it is datable by both the beta counting and accelerator mass spectrometry (AMS) techniques. Large material resources of charcoal have yielded a large number of ${ }^{14} \mathrm{C}$ dates, as we will later see. One of the advantages of AMS dating is the possibility to date food residues and other organic remains in ceramic vessels. In Finland, the composition of these residues has rarely been analyzed, so the residues are usually called "charred crust" with the exception of shiny black birch-bark tar, which has been used as sealing putty for broken vessels (Pesonen 1999; Reunanen 1999). The same material is occasionally found in small lumps with impressions of teeth-hence the name "chewing resin.” In all, some differences are expected to show up between the temporal sample-specific distributions of ${ }^{14} \mathrm{C}$ dates.

Certain dated materials may have had considerable age of their own before they were actually used in prehistoric times. The most obvious is the use of deadwood in camp fires. This possibility must be taken seriously in northern areas in particular, where deadwood as old as hundreds of years may have been collected for firewood (see Carpelan 2004a:37-41). Deadwood and/or recycled wood may also have been used for wooden structures. Typical dated wooden objects are skis, sledge runners, and the like, in which using deadwood would be strange. In such a case, the own-age effect of wood and its derivatives (like charcoal) would be restricted by the short intrinsic lifetime of freshly cut wood. Charred crust and birch-bark tar are probably the most accurate dating materials from the 
point of view of own age: charred crust is derived from animals and young plants, and birch-bark tar is made from the fresh new outer layer of birch tree bark (e.g. Reunanen 1999; Hopia et al. 2003).

Some natural processes may also have affected the visibility of archaeological material in our research area. One notable factor here is the transgressions that took place in many of the lake basins during the Holocene (Saarnisto 1971). The most extensive of these was the transgression that took place about 8000-4000 cal BC in the Saimaa Lake complex (Saarnisto 1970). The lake buried whole sequences of settlement history in large areas of eastern Finland. Finally, the effects of prehistoric mobility patterns must be considered because it is reasonable to assume that mobile hunter-gatherer groups left behind more sites in a given time than sedentary groups. However, in this paper we concentrate merely on the usefulness of ${ }^{14} \mathrm{C}$ dates in terms of research priorities, deterioration, and ownage effects. We intentionally avoid archaeological interpretations to which the geographical and prehistorical considerations may lead us. These interpretations are presented in another article (Tallavaara et al. 2010).

There is an issue that is not dealt with in the present work, namely reservoir effects. Due to fossil carbonates incorporated in marine/freshwater sediments and via the foodchain in even humans, older ${ }^{14} \mathrm{C}$ ages have been determined for samples dependent on aquatic resources (Cook et al. 2001 and references therein). Unfortunately, the specificity of the present data does not allow for investigating the reservoir effects, but the need for a considerable effort in the future is realized.

\section{METHODS}

\section{Radiocarbon Data}

Archaeological ${ }^{14} \mathrm{C}$ analyses performed at the Dating Laboratory (Finnish Museum of Natural History, University of Helsinki) forms the backbone (80\%) of the used ${ }^{14} \mathrm{C}$ data set. The analyses at the Dating Laboratory in Helsinki were performed with conventional beta counting techniques (Helcode) until 2003. Analyses by accelerator mass spectrometry (AMS, Hela- code) commenced in 1994, and the technique took over completely by 2004. The data have been published as date lists (Jungner 1979; Jungner and Sonninen 1983, 1989, 1996, 1998, 2004) up to Hel-4132 and Hela-154. The data set was extended to cover — as thoroughly as possible - the other published archaeological ${ }^{14} \mathrm{C}$ dates from the eastern Fennoscandian territory measured either at the Dating Laboratory or elsewhere. In addition, the data contain also those unpublished dates that have been kindly released for our use by many Dating Laboratory customers.

Altogether, the collected database consists of 2565 individual ${ }^{14} \mathrm{C}$ dates forming a timeline for the period from the earliest colonization in $\sim 9000 \mathrm{BC}$ to the modern era. The data set also includes the last millennium to highlight the material differences, and therefore differs slightly from the set used by Tallavaara et al. (2010). The database is strongly governed by charcoal finds: of the original data, $55 \%$ is from charcoal dates. Wood samples represent another large fraction of dates amounting to $13.5 \%$. Other sample materials are mostly charred crust, bone, cremated bone, and birch tar. The shares of these remain below $8 \%$ each.

Within the gathered database, we have intentionally avoided to make any a priori exclusive selections on the dates. Instead, we have relied on the archaeological scrutiny contemporaneous with the sample selection to establish a link between the dated sample and the archaeological context. This approach is justified, since possible erroneous selections are expected to form a clear minority within the data set studied, and their role is merely statistical, not systematical. Furthermore, we have trusted in the scientifically proven quality control methods of the ${ }^{14} \mathrm{C}$ community to reveal erroneous ${ }^{14} \mathrm{C}$ results. The ${ }^{14} \mathrm{C}$ sample pretreatments and analyses have been carried out by using 
well-established methods that have been subjected to numerous international intercomparison studies over the years (e.g. Scott et al. 2007).

Fractionation corrections were not originally made for the Hel dates obtained before 1987. Thus, the measured $\delta^{13} \mathrm{C}$ values for each sample material type have been averaged and the average values have been used to correct for the fractionation effects for those results. In displaying the frequency distributions, 100-yr time intervals have been used and the temporal axis is presented as uncalibrated in units of years before present (BP) (Stuiver and Polach 1977). Displaying the calendar year probability distributions has been done in our parallel study concentrating on the archaeological interpretations of the data (Tallavaara et al. 2010). Quantitative information on similarities between temporal date distributions has been obtained by performing linear correlation analyses.

\section{Analyses on Effects of Research Interests}

The data produced by the Helsinki Dating Laboratory (codes Hel-/Hela-) includes the most complete information on, for instance, sample submitters and submission dates within the total data set. This data (1979 ${ }^{14} \mathrm{C}$ dates) forms a representative sample of the total data, and it has been used to investigate changes in the date distribution over decades and the effects of research interests. The linear correlation coefficient between the chosen data set (1979 dates) and the total data set (2565 dates) is $R=0.99$, thus well justifying the selection.

As the highest cultural heritage authority in Finland, the National Board of Antiquities (NBA) governs most of the archaeological surveys and rescue excavations. In such studies, there should not be major a priori preferences set over any archaeological period. Therefore, a data set formed by the single NBA-submitted dates is expected to reflect essentially a temporally unbiased date distribution. These individual dates have been selected from the database, and specifically the dates belonging to any larger date series have been disregarded. The selected data set has been used as a reference for correlation analyses to evaluate the effects of research interests.

Varying interests are typically realized through more individual efforts (e.g. PhD theses/personal grants) and/or through collaborative research (larger projects). Both types have been studied to shed light on the origin of possible biases. The Hel/Hela archaeological database consists of results of dated samples from 143 suppliers. The data have been split into two in order to study possible researcher dependencies: one half by the most active 16 researchers and another by the remaining 127. Each subset is assumed to suffer from researcher-dependent biases. It is also assumed that by summing a large number of small subsets of data, one approaches a situation in which possible researcher dependencies would cancel out. On the other hand, by summing a small number of large subsets of data, possible researcher dependencies are expected to be seen more prominently. In addition, as an example of the possible project-dependent biases, we have taken a look at the largest individual project producing and concentrating on ${ }^{14} \mathrm{C}$ dates in Finland over the last $20 \mathrm{yr}$ - the Early in the North project (Carpelan 2004b) — to reveal its role in the resulting total date distribution.

To shed light on possible changes in date distributions over the last $40 \mathrm{yr}$ of ${ }^{14} \mathrm{C}$ dating within eastern Fennoscandia, the data set has been eventually divided according to the decade during which the sample was submitted to the laboratory. We expect the changes in research interests or other systematical effects over the years to show up, altering the shape of the date distribution over the decades.

\section{Material Dependencies}

The distributions have been presented separately for bone, charcoal, charred crust, cremated bone, and wood to illustrate the sample material-dependent effects on the date distributions. The analysis 
has been compiled on the total data set of $2565{ }^{14} \mathrm{C}$ dates by concluding on the sample materials mostly suffering from taphonomic effects and attempting the relevant corrections. The correction procedure for taphonomic effects is adopted from Surovell et al. (2009). They used a database of ${ }^{14} \mathrm{C}$-dated volcanic deposits from Bryson et al. (2006) and have developed an empirical model of taphonomic bias by arguing that the site destruction probability decreases with site age instead of the previous assumption of a constant rate of destruction (Surovell and Brantingham 2007). Particularly, their core result can be expressed as

$$
n_{t}=5.726442 \times 10^{6}(t+2176.4)^{-1.3925309}
$$

where $n_{t}$ is the number of ${ }^{14} \mathrm{C}$ dates surviving from time $t$.

We have modified Equation 1 slightly to make it better correspond to the data set of the last 10,000 ${ }^{14} \mathrm{C}$ yr. The same ${ }^{14} \mathrm{C}$ dates of the volcanic deposits from the Bryson data set have been used, but in the age range of 200-10,000 BP. On these uncalibrated data, the same fit is performed as Surovell et al. (2009). This yields a slightly modified equation for $n_{t}$ :

$$
n_{t}=9.033327 \times 10^{10}(t+7640.7)^{-2.4114}
$$

The new $n_{t}$ has been calculated by using Equation 2 for the selected subsets of data. For each time interval of the date distribution, the number of observed ${ }^{14} \mathrm{C}$ ages has been divided by this value $n_{t}$ for the median year of that temporal interval. Finally, the obtained results have been normalized by matching their sum to unity for all the distributions.

\section{Analysis for Own-Age Effects}

Estimations of the centroids of local maxima in the date distributions were performed as follows. Following the guideline of avoiding any a priori prejudices concerning the date distributions, dates were assumed to be distributed normally around the true local maximum of the distribution. Thus, Gaussian shapes were fitted into these local maxima to estimate their centroids. Whereas non-normal distributions can, and most likely do, appear, their effect on the centroid analyses should remain within the statistical uncertainty of an individual ${ }^{14} \mathrm{C}$ date, and thus Gaussian fit seems reasonable.

Particularly, in the estimation of the wood and charcoal own age, it proceeded as follows. First, the combined wood and charcoal date distribution was assumed to reflect the possible own-age effects present. The data were therefore split into 2 data sets: 1 ) dates of wood and charcoal samples and 2) all the remaining dates of samples with assumed shorter intrinsic life. A characteristic peak at $\sim 5000 \mathrm{BP}$ in the distribution was used to estimate the magnitude of the cumulative own-age effect. It is expected that the possible cumulative sample own age should shift the peak towards the older age. The own-age effect was estimated as the difference between the centroids of Gaussian fits for data sets a) and b) on the region 3500-6500 BP. The eventual uncertainty of the own-age effect was determined by quadratic summing of centroid uncertainties at a $1-\sigma$ level.

\section{RESULTS AND DISCUSSION}

\section{Amount of Data}

The collected set of ${ }^{14} \mathrm{C}$ dates geographically covers Finland, the Karelian Isthmus, and southwestern parts of the Karelian Republic (Figure 1). For the sake of simplicity, the term "eastern Fennoscandia" is used to describe the territory included. This is also consistent with a parallel study by Tallavaara et al. (2010). The data set in this study contains 2565 individual ${ }^{14} \mathrm{C}$ dates. The amount of 
available data could be compared to the demographic studies in Germany, Poland, and Denmark performed by Shennan and Edinborough (2007): 1709, 214, and 388, respectively. We assume that the size of our data forms a reasonable foundation to begin population history studies.

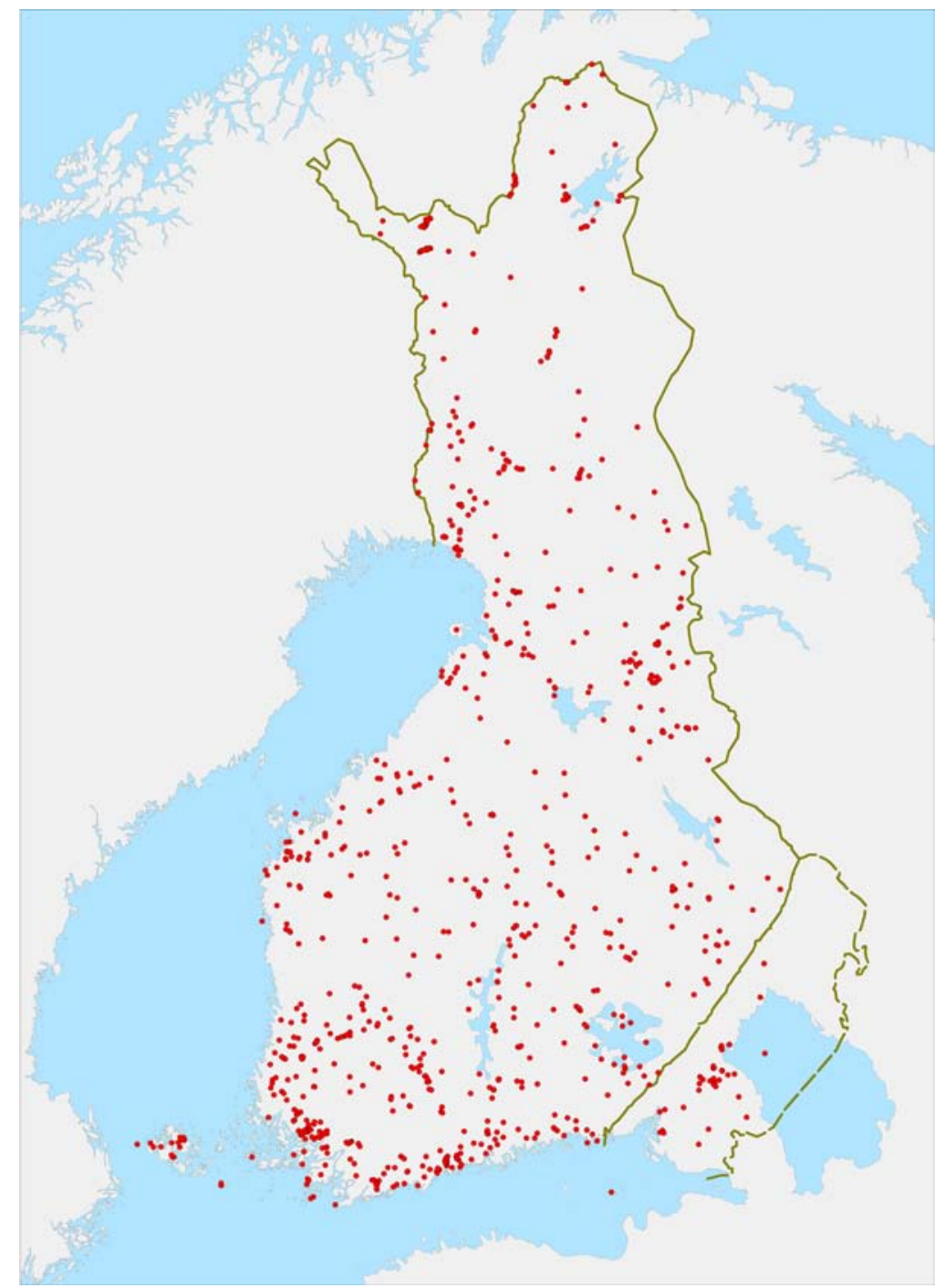

Figure 1 Geographical distribution of the collected dates in the database. The total number of individual dates is 2565 .

\section{Temporal Distribution}

The temporal distribution of the total data set and charcoal data set is presented in Figure 2. The total distribution is strongly governed by results of charcoal samples since they account for more than half of the data. The most outstanding feature of the temporal date distribution is a local maximum at $~ 5000$ BP. The age corresponds to the beginning of the Typical Comb Ware period of eastern Fennoscandian prehistory (e.g. Carpelan 1999). This peak is followed by a decline towards 3400 BP. 
The number of dates rises again through the Metal Ages and towards another local maximum around 2000-1800 BP. The observed peak and the successive minimum are very distinctive features of the distribution. In the following discussion, we mainly concentrate on the most outstanding feature of the distributions: the local maximum around 5000 BP, i.e. the Stone Age peak.

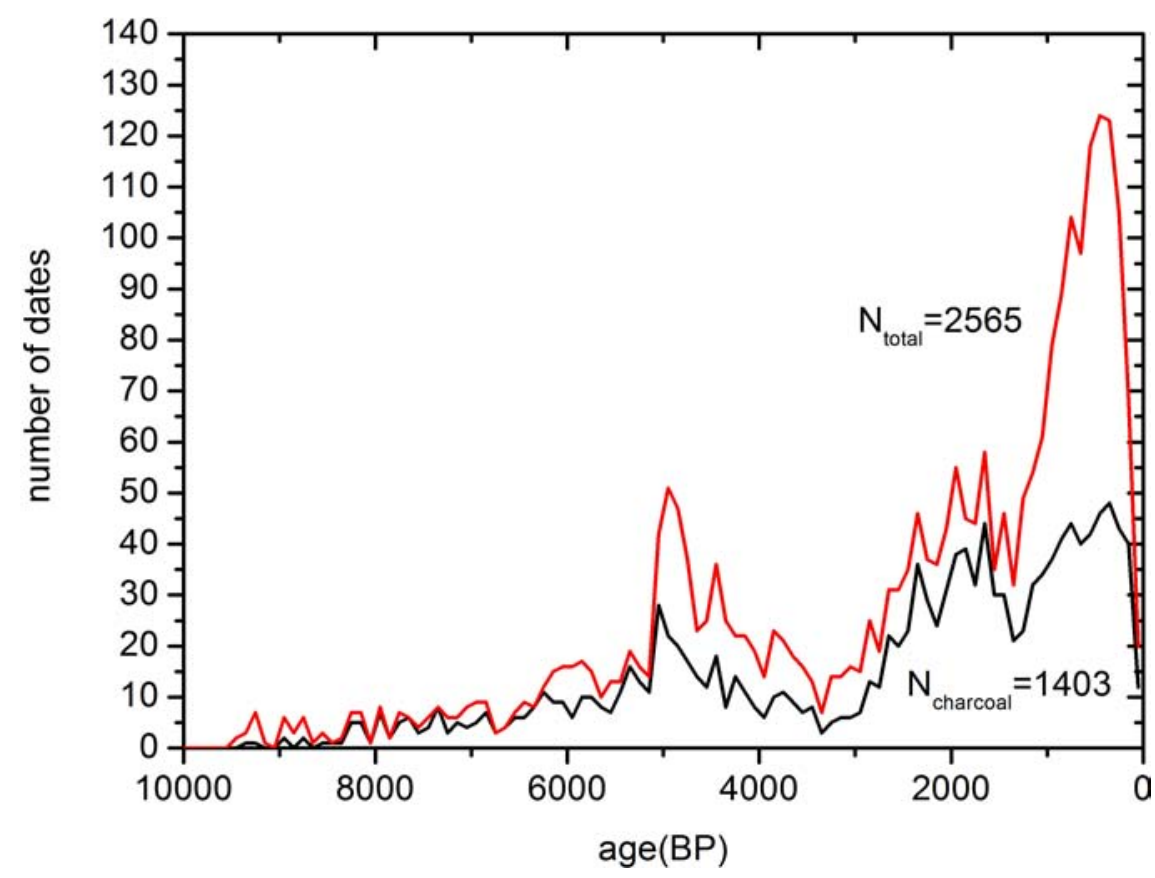

Figure 2 Comparison of the temporal distributions of all the ${ }^{14} \mathrm{C}$ dates and the dates obtained from charcoal samples.

\section{Research Interests}

We take a detailed look at the role of research interests in the formation of the observed pattern by examining the ${ }^{14} \mathrm{C}$ date records of the National Board of Antiquities and the most active researchers and projects (Figure 3 ).

As pointed out earlier, the data set of individual ${ }^{14} \mathrm{C}$ dates by the National Board of Antiquities should reflect the archaeological surveys and rescue excavations done without emphasis on certain periods. Therefore, it can be considered a representative subset of such basic archaeological fieldwork done in eastern Fennoscandia, and thus should give an unbiased view of the temporal distribution of the performed ${ }^{14} \mathrm{C}$ analyses. The distribution (Figure 3a) shows a similar pattern compared to the total data (Figure 3b). Particularly, the Stone Age peak starts to reveal itself already within this data set and it is followed by a decline towards $4000 \mathrm{BP}$. This visual observation of pattern resemblance is supported by a correlation analysis that results in $R=0.87$.

The Stone Age peak is, however, more outstanding in the total data (Figure 3b). It seems that the structure is due to the most active sample submitters (Figure 3c). The general trend in Figure 3d (the other 127 submitters) appears to be fairly similar, although the peak is not as well resolved. This is reasonable since the former distribution is due to some of the most prominent characters of Finnish archaeology within the last $40 \mathrm{yr}$, and their fingerprints should definitely be visible in the data. Indeed, the sharpening of the observed structures in Figure $3 c$ illustrate the role of these individuals 


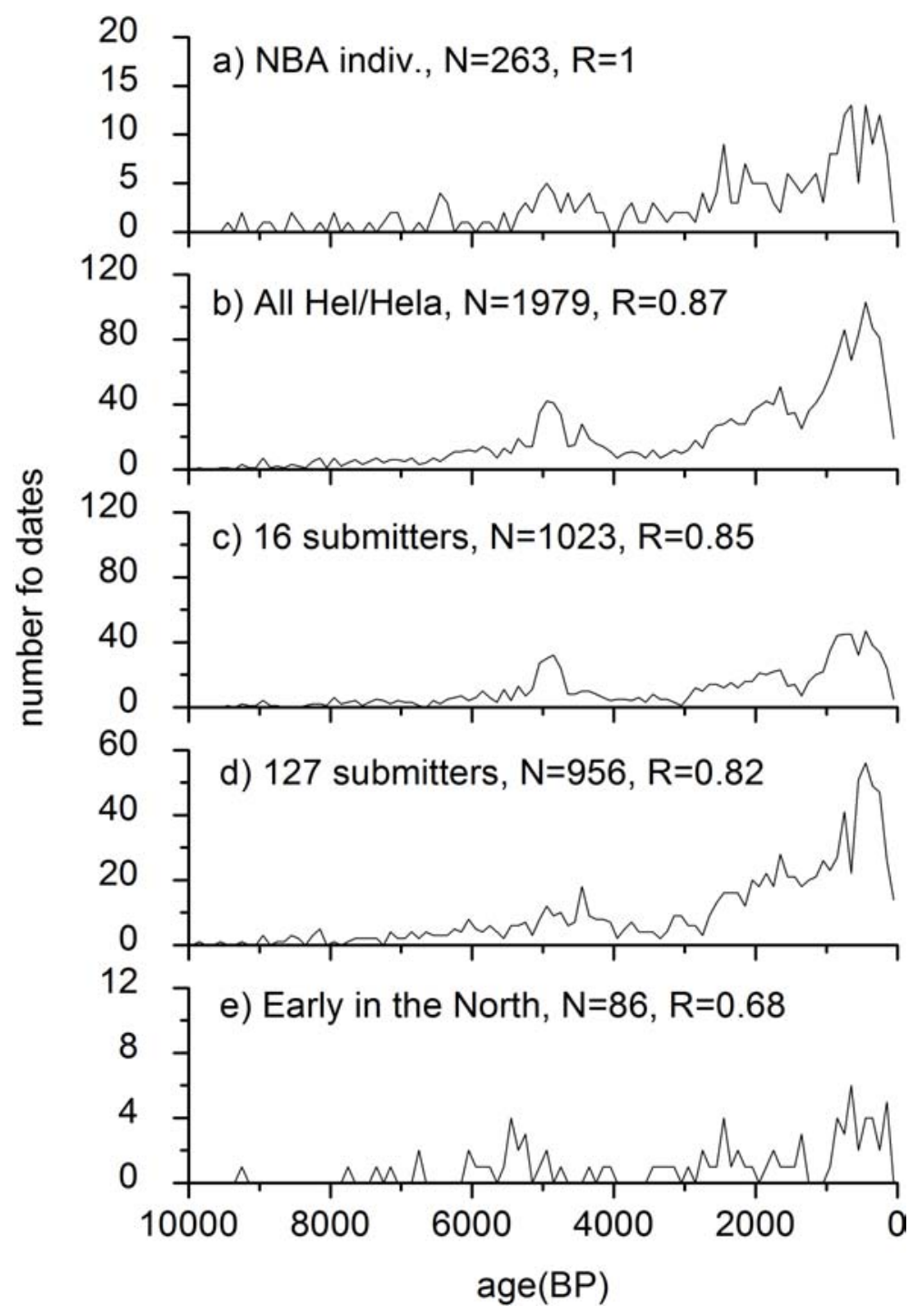

Figure 3 Temporal distributions of Hel/Hela dates (Dating Laboratory, Helsinki) sorted by various criteria (see text). $\mathrm{N}=$ number of ${ }^{14} \mathrm{C}$ dates; $\mathrm{R}=$ linear correlation coefficient between the given data and data in a).

in shaping archaeological research in Finland. If we assume that Figure 3a represents an unbiased date distribution, the observed changes towards a total distribution (Figure 3b) and the distribution due to the 16 most active researchers (Figure 3c) reflect personal or institutional research interests. Whether or not to call this a bias is merely a matter of perspective-we think it would be unfair towards the most active archaeologists and institutes to categorize their work as less useful with respect to the population historical studies. Nevertheless, this massive data set definitely has a flavor of personal and institutional research interests.

Concerning the research projects within the last $20 \mathrm{yr}$, clearly the largest individual one producing samples for ${ }^{14} \mathrm{C}$ analyses has been the Early in the North project (Carpelan 2004b) during 1994- 
1998. It has produced $\sim 5 \%$ of all the dates in the data set. When comparing the resulting date distribution (Figure 3e) to the decadal distribution of the 1990s (Figure 4b), temporal biasing resulting in the Stone Age peak in particular seems negligible. In contrast, the relatively low correlation coefficient $(R=0.68)$ indicates a somewhat different pattern and, indeed, the project did concentrate on the prehistory of northern parts of Finland. The differing pattern seems to be due to this geographical setting, and this deserves a more thorough archaeological interpretation (see Tallavaara et al. 2010). No other research project stands out from the data set and the share of any of them remains below $5 \%$. Thus, their effect is expected to be fairly insignificant.

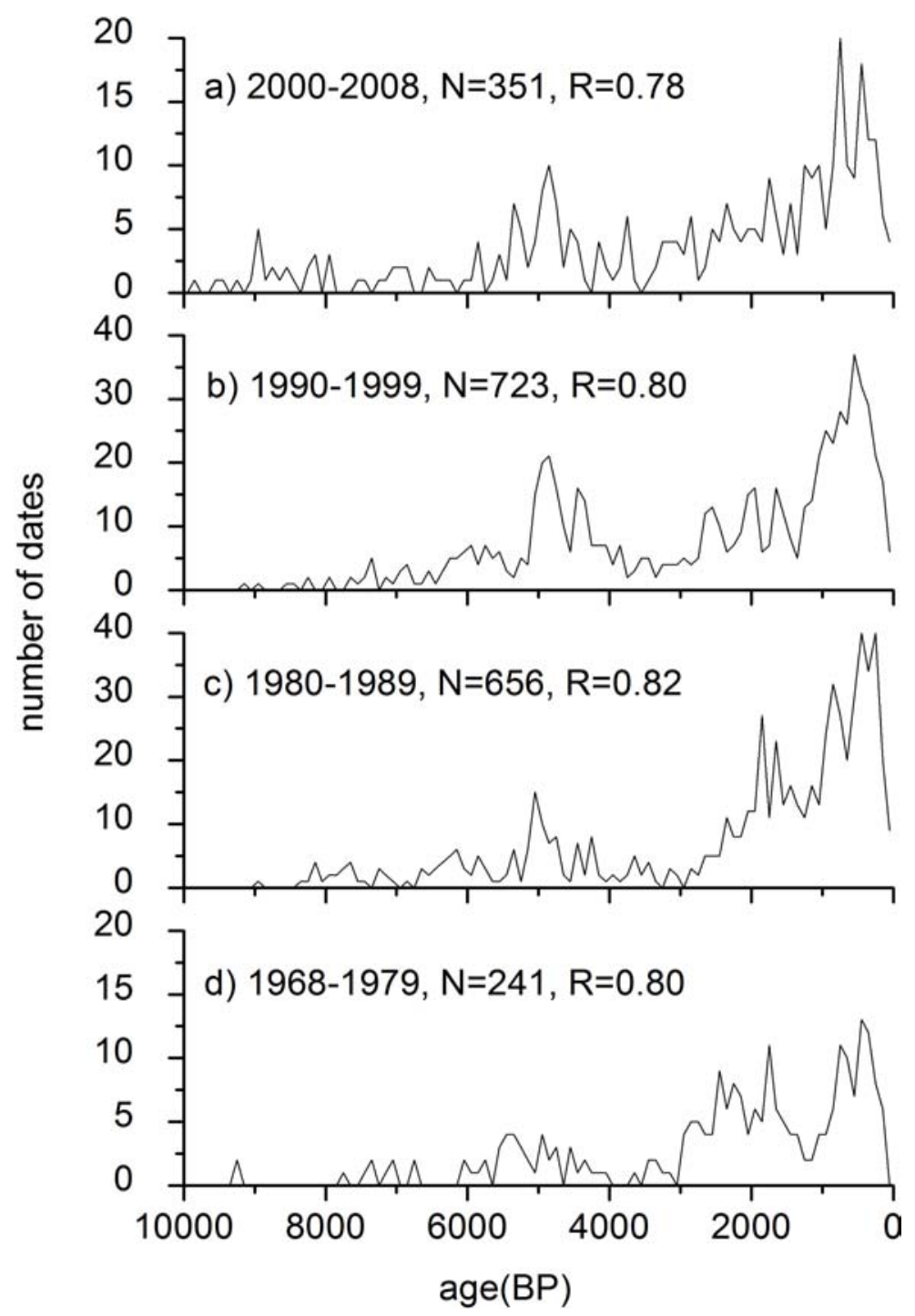

Figure 4 The Hel/Hela date distributions (Dating Laboratory, Helsinki) grouped according to the submission decade. $\mathrm{N}=$ number of ${ }^{14} \mathrm{C}$ dates, $\mathrm{R}=$ linear correlation coefficient between the given data and data in Figure 3a). 
Decadal date distributions over these years are displayed in Figure 4. The pattern visible in the total data set with the Stone Age peak appears also in the decadally grouped data. Particularly, it is shown during the last 3 decades, but there is clear concentration of dates between 6000 to $4000 \mathrm{BP}$ as early as in the distribution of years 1968-1979. However, the distribution of dates corresponding to sample submission years 1968-1979 suffers from low statistics and possibly also from inappropriate sample selection procedures at the dawn of ${ }^{14} \mathrm{C}$ analyses in Finland (Jungner 1976). Nevertheless, the general pattern seems to be similar to the other subsets. A visual analysis can be quantitatively verified by correlation analyses. The linear correlation coefficients between the decadal data sets and our reference distribution are consistently within $0.78-0.82$. This shows that the ${ }^{14} \mathrm{C}$ analyses for eastern Fennoscandian sites have, decade by decade, yielded a nearly identical distribution pattern. It is also worthwhile to note the increase of old dates $(10,000-8000 \mathrm{BP})$ in the beginning of the new millennium. This is mostly due to the availability of a cremated bone pretreatment procedure that was established recently (Lanting 2001) and adopted subsequently in Finland (Jungner 2003).

\section{Material-Dependent Effects}

Few ski/boat finds exist with ages that predate 2000 BP (Figure 5a). This is due to wood degradation. Similarly, unburned bones suffer from the naturally acidic soil of eastern Fennoscandia and, therefore, the bone date distribution peaks strongly in the last millennium (Figure 5b). Due to their resistance to environmental challenges, charcoal, cremated bone, and charred crust samples provide better tools for studying the origins of the colonization of eastern Fennoscandia. In particular, charcoal data dominate the total distribution in the region of 9000-2000 BP. Cremated bone samples date back to the earliest phases of colonization ( 9500 BP). The sharp emergence of charred crust dates in the date distribution at $\sim 6250$ BP corresponds to the earliest use of pottery.

It is also apparent that relying on bone and wood samples alone would give a very distorted picture of the archaeological record for the Holocene period in the area. The peaking of bone and wood sample results to ages $<2000 \mathrm{BP}$ motivates us to examine the correction procedure suggested by Surovell et al. (2009) for taphonomic biases (Figure 6).

It seems that local maxima are somewhat present in the corrected frequency distributions of both bone and wood samples within the range 3000-6000 BP, as also observed for charcoal data. However, low statistics in both the bone and wood data do not allow us to determine whether a similar Stone Age peak took place in 5000 BP. If we adopt the degradation rates of wood presented by Jurgensen et al. (2004) for Finland, Stone Age wooden findings in eastern Fennoscandia should not exist at all. Nevertheless, they do, and the explanation seems to lie with anaerobic bogs where some rare Stone Age samples have been preserved. The relative enhancement of both the bone and wood

data within $<1000$ BP may result from a preferable selection of material for dating: bone and wood may be preferred over charcoal for various reasons. Dendrochronology could potentially be applied to well-preserved wood samples or they could be identified even taxonomically. Such investigations also form a solid foundation for ${ }^{14} \mathrm{C}$ dating. Having a shorter intrinsic life, bone samples often take precedence over charcoal and also enable dietary studies with stable isotopes, which makes them scientifically more interesting.

It is clear from Figure 6, however, that the identical correction procedure works differently with all sample materials. In fact, the ${ }^{14} \mathrm{C}$ data used to obtain the taphonomic correction are derived from volcanic deposits, and therefore, among all archaeological sample materials, charred samples should be the ones in which correction should work well since their taphonomic rate is presumably similar. However, the procedure seems to overcorrect the charcoal distribution, and corrected data would even indicate Stone Age human activity exceeding that in the Metal Age and even in the Middle 


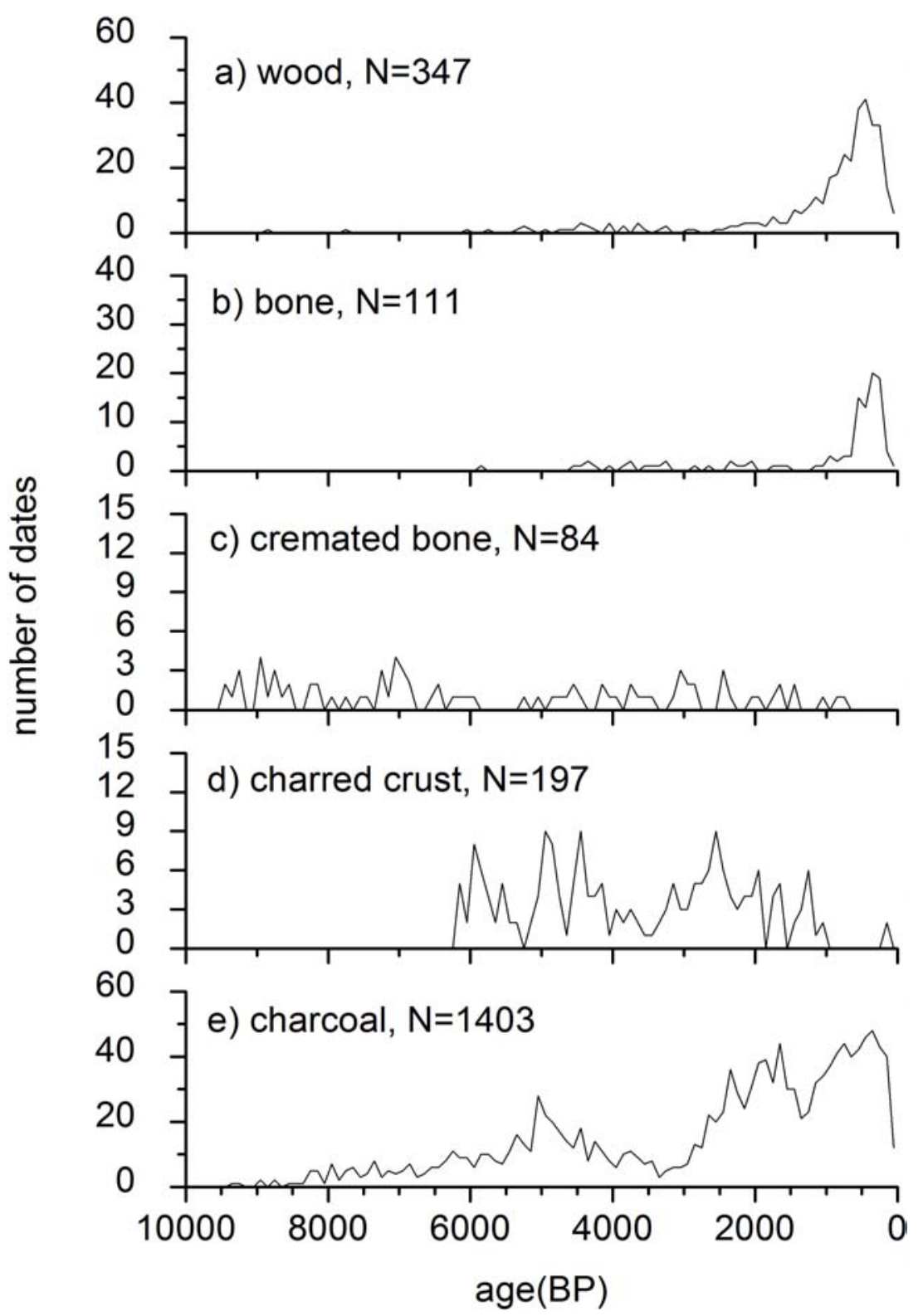

Figure 5 Date distributions of wood, bone, cremated bone, charred crust, and charcoal samples

Ages, which is hard to digest. Thus, we realize the need of material-dependent degradation rates to further improve the correction procedure for the data set, if it is to be applied. On the basis of our analysis, we are hesitant to determine the proper magnitude of possible correction for a certain sample material type, or whether it should be applied at all. For instance, charcoal samples in our data seem to survive better compared to the volcanic deposits on which the correction procedure is based. 


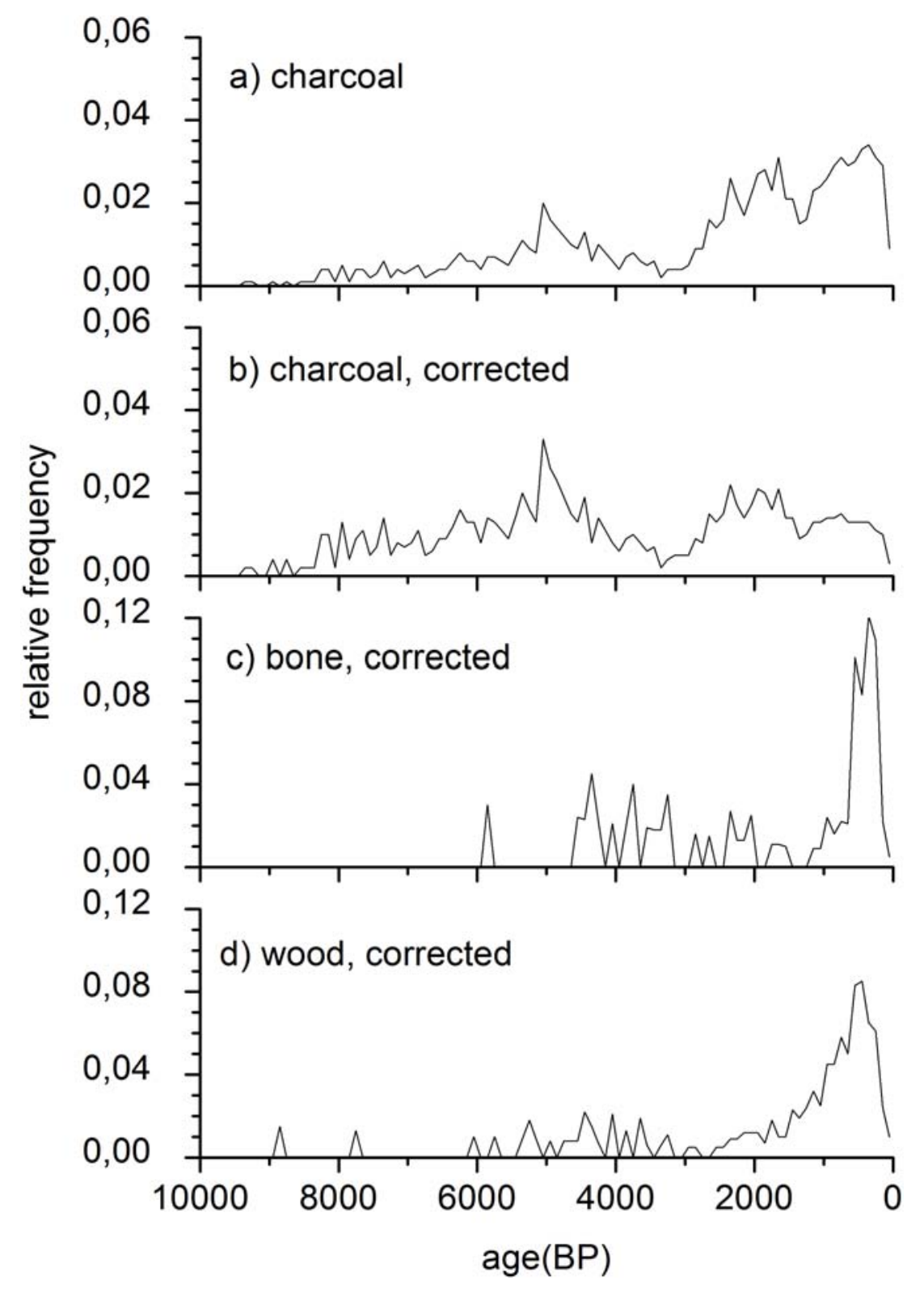

Figure 6 Comparison of the taphonomically corrected ${ }^{14} \mathrm{C}$ ages of charcoal, bone, and wood samples with the uncorrected results of charcoal samples. The results are normalized $(\Sigma=1)$.

\section{Own-Age Effects}

As expected, the Stone Age peak centroid of the charcoal/wood data set (4929 \pm 76 BP) is shifted towards the older ages by $42 \pm 79{ }^{14} \mathrm{C}$ yr $(1 \sigma$, Figure 7$)$ with respect to the corresponding peak centroid in the rest of the data $(4887 \pm 21 \mathrm{BP})$. The obtained average own age can be caused by individual wood/charcoal sample own ages that, on average, have low values but for which the individual own ages (the distribution tails) can be spread out by up to $240{ }^{14} \mathrm{C}$ yr (with 3- $\sigma$ confidence). 


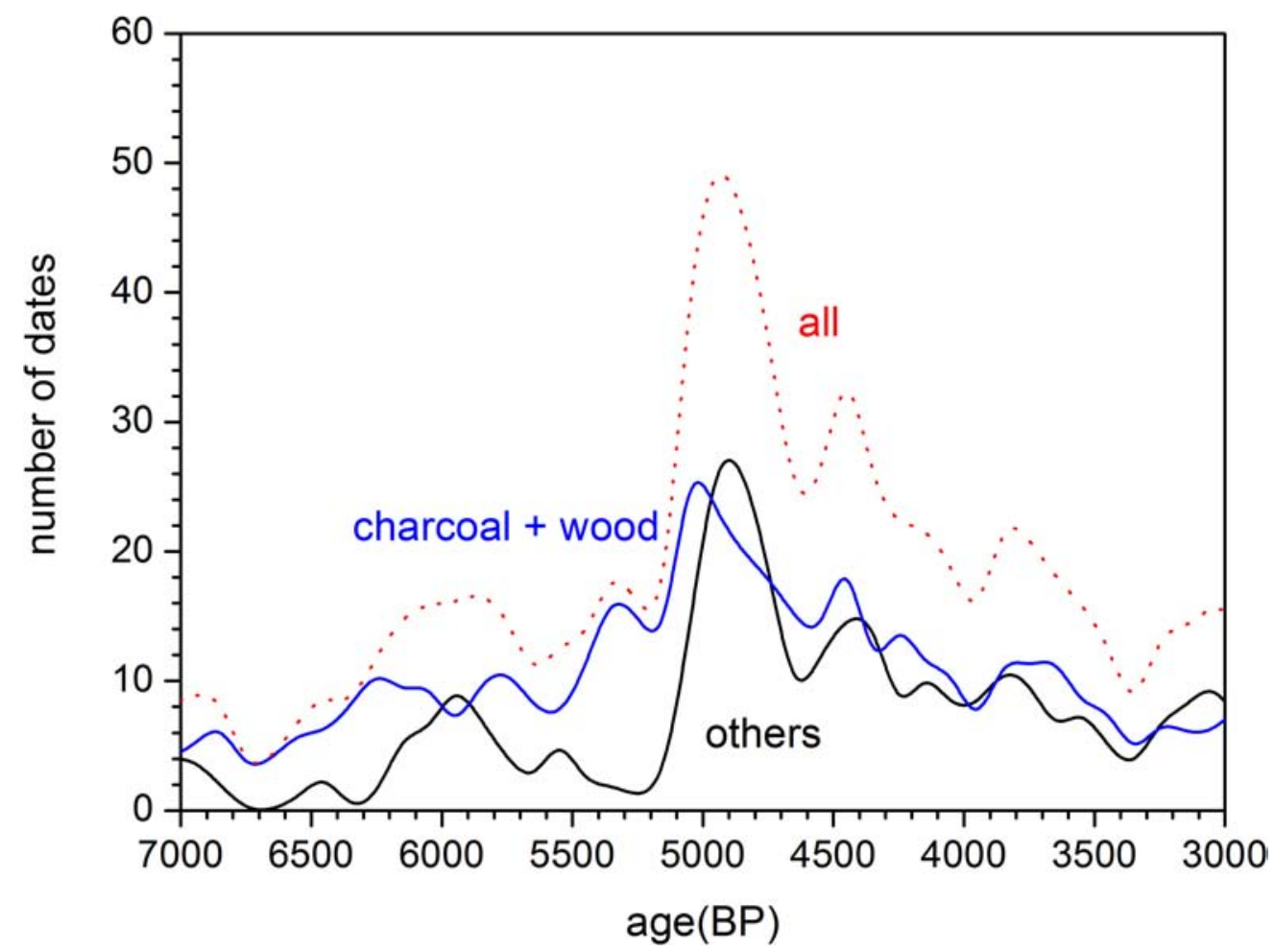

Figure 7 Estimation of the average own-age effect for dates of wood/charcoal samples. The data within 6500-3500 BP contains 381 and $260{ }^{14} \mathrm{C}$ dates for wood/charcoal and others, respectively.

When combining all the data together, the Stone Age peak centroid (4907 \pm 21 BP) falls in between the above values. The typical uncertainty of an individual ${ }^{14} \mathrm{C}$ analysis with an age of $5000 \mathrm{BP}$ is \pm 50 ${ }^{14} \mathrm{C}$ yr and larger than the overall influence of the wood/charcoal data. Therefore, we consider the observed own-age contribution to be fairly insignificant in the context of population history studies for the observed local maximum. However, we also note that the own age is known to be present for individual samples with intrinsic life, and therefore, it should be preferably considered separately for individual contexts. Furthermore, effects may be culture and time dependent, although the statistics of our data allow for studies of the Stone Age peak only.

\section{CONCLUSIONS}

The overall picture is consistent with the following. Individual dates by the National Board of Antiquities, and to some extent also the small data subsets (the 127 subsets), yield more or less similar date distributions that already reveal the local maximum around $5000 \mathrm{BP}$. These possibly reflect the results of the more or less temporally random archaeological surveys and rescue excavations. The basic archaeological fieldwork forms a foundation for further and more thorough archaeological research that eventually shapes the temporal distribution of ${ }^{14} \mathrm{C}$ dates. We observe an outstanding Stone Age peak in practically all the displayed date distributions. It has its origin in the longstanding and prevalent research effort that is manifested by the observed stability of decadal distribution patterns. Whereas some research interest biases in the patterns cannot be ruled out, this is not a solid enough argument to exclude data that definitely carries mostly relevant and representative information on the archaeological record collected during the last $40 \mathrm{yr}$. Indeed, the stability of the observed 
distribution patterns indicates something else: it is hard to believe such a pattern to emerge without a positive correlation to prehistorical population levels.

Due to their resistance to environmental challenges, charcoal, cremated bone, and charred crust samples provide the most useful tools for studying the origins of the colonization of eastern Fennoscandia. Material-dependent effects are visible but screened by the dominance of charcoal data in the age range 9000-2000 BP. Due to sample degradation, old wood and bone dates are rare, but these materials start to dominate the total distribution for ages younger than 2000 BP. Because of these sample material differences, equal taphonomic corrections based on ${ }^{14} \mathrm{C}$-dated volcanic deposits cannot account for all the sample degradation effects, and hence, material-dependent correction procedures are suggested. The own age of wood and charcoal samples is visible in the observed Stone Age maximum, but it seems to be too modest to have a significant effect on the demographic conclusions on it.

Overall, keeping in mind the above discussion, we believe our research has shown a solid temporal distribution pattern of archaeological ${ }^{14} \mathrm{C}$ dates in eastern Fennoscandia, on which archaeological interpretations and spatiotemporal modeling can be based.

\section{ACKNOWLEDGMENTS}

MO would like to thank Högne Jungner, Eloni Sonninen, and all past and present personnel of the Dating Laboratory for their hard work in ${ }^{14} \mathrm{C}$ analyses over the years. PP and MT would like to thank Päivi Onkamo and her Argeopop project for partly funding their research. In addition, we would like to thank Dating Laboratory customers for allowing us to use their unpublished data, and 3 anonymous reviewers for their invaluable comments.

\section{REFERENCES}

Bryson RU, Bryson RA, Ruter A. 2006. A calibrated radiocarbon database of late Quaternary volcanic eruptions. eEarth Discussions 1:123-34.

Carpelan C. 1999. Käännekohtia Suomen esihistoriassa aikavälillä 5100-1000 eKr. In: Fogelberg P, editor. Pohjan Poluilla: Suomalaisten juuret nykytutkimuksen mukaan. Bidrag till kännedom av Finlands natur och folk 153. Helsinki: Suomen Tiedeseura. p 249-80.

Carpelan C. 2004a. Environment, archaeology and radiocarbon dates. Notes from the Inari region, northern Finnish Lapland. In: Lavento M, editor. Early in the North. ISKOS 13. Helsinki: Finnish Antiquarian Society. p 17-46.

Carpelan C. 2004b. The Early in the North Projectbackground and objectives. In: Lavento M, editor. Early in the North. ISKOS 13. Helsinki: Finnish Antiquarian Society. p 9-16.

Cook GT, Bonsall C, Hedges REM, McSweeney K, Boroneant V, Pettitt PB. 2001. A freshwater diet-derived ${ }^{14} \mathrm{C}$ reservoir effect at the Stone Age sites in the Iron Gates Gorge. Radiocarbon 43(2A):453-60.

Fiedel SJ, Kuzmin YV. 2007. Radiocarbon date frequency as an index of intensity of Paleolithic occupation of Siberia: Did humans react predictably to climate oscillations? Radiocarbon 49(2):741-56.

Gamble C, Davies W, Pettitt P, Hazelwood L, Richards M. 2005. The archaeological and genetic foundations of the European population during the Late Glacial: implications for 'agricultural thinking.' Cambridge Archaeological Journal 15(2):193-223.

Hopia A, Reunanen M, Pesonen P. 2003. GC-MS analysis of organic residues in the potsherd samples from Vantaa Maarinkunnas. Finskt Museum 1995. p. 44-55.

Jungner H. 1976. In: Proceedings of the Nordic Conference on Thermoluminescence Dating and Other Archaeometric Methods. Uppsala, 1976.

Jungner H. 1979. Radiocarbon dates I. Report no. 1, Dating Laboratory, University of Helsinki. ISBN 951-451616-8.

Jungner H. 2003. Uusia ajatuksia vanhoista luista. Arkeologiapäivät 2003. p 6-9. http://www.sarks.fi/ap/ ap2003/ap2003_02_junger.pdf.

Jungner H, Sonninen E. 1983. Radiocarbon dates II. Report no. 2, Dating Laboratory, University of Helsinki. ISBN 951-45-2877-8.

Jungner H, Sonninen E. 1989. Radiocarbon dates III. Report no. 3, Dating Laboratory, University of Helsinki. ISBN 951-45-5197-4.

Jungner H, Sonninen E. 1996. Radiocarbon dates IV. Report no. 4, Dating Laboratory, University of Helsinki. ISBN 951-45-7383-8.

Jungner H, Sonninen E. 1998. Radiocarbon dates V. Report no. 5, Dating Laboratory, University of Helsinki. ISBN 951-45-8462-7. 
Jungner H, Sonninen E. 2004. Radiocarbon dates VI. Report no. 6, Dating Laboratory, University of Helsinki. ISBN 952-10-1769-4.

Jurgensen M, Laks P, Reed D, Collins A, Page-Dumrose D, Crawford D. 2004. Chemical, physical and biological factors affecting wood decomposition in forest soils. Presented at IRG 35, 6-10 June 2004, Ljubljana, Slovenia. Stockholm: The International Research Group on Wood Preservation. http://www. treesearch.fs.fed.us/pubs/22120.

Lanting JN, Aerts-Bijma AT, van der Plicht J. 2001. Dating of cremated bones. Radiocarbon 43(2A):24954.

Mays S. 1998. The Archaeology of Human Bones. Abingdon: Routledge.

Onkamo P, et al. 2008. Argeopop: Finnish pre-history reconstructed in the light of archeological and population genetic data. URL: http://www.helsinki.fi/bioscience/argeopop/index.htm.

Pesonen P. 1999. Radiocarbon dating of birch bark pitches in typical comb ware in Finland. In: Ranta H, editor. Dig it All. Papers dedicated to Ari Siiriäinen. Helsinki: The Finnish Antiquarian Society. p 191-7.

Reunanen M. 1999. Analysis of the pitch sample [Appendix 1 in Pesonen 1999]. In: Ranta H, editor. Dig it All. Papers dedicated to Ari Siiriäinen. Helsinki: The Finnish Antiquarian Society. p 197-9.
Saarnisto M. 1970. The Late Weichselian and Flandrian history of the Saimaa Lake complex. Commentationes Physico-Mathematicae 37:1-107.

Saarnisto M. 1971. The history of Finnish lakes and Lake Ladoga. Commentationes Physico-Mathematicae 41(4):371-88.

Scott EM, Gordon GT, Naysmith P, Bryant C, O’Donnell D. 2007. A report on Phase 1 of the 5th International Radiocarbon Intercomparison (VIRI). Radiocarbon 49(2):409-26

Shennan S, Edinborough K. 2007. Prehistoric population history: from the Late Glacial to the Late Neolithic in Central and Northern Europe. Journal of Archaeological Science 34(8):1339-45.

Surovell TA, Brantingham PJ. 2007. A note on the use of temporal frequency distributions in studies of prehistoric demography. Journal of Archaeological Science 34(11):1868-77.

Stuiver M, Polach HA. 1977. Discussion: reporting of ${ }^{14} \mathrm{C}$ data. Radiocarbon 19(3):355-63.

Surovell TA, Finley J, Smith GM, Jeffrey Brantingham P, Kelly R. 2009. Correcting temporal frequency distributions for taphonomic bias. Journal of Archaeological Science 36(8):1715-24.

Tallavaara M, Pesonen P, Oinonen M. 2010. Prehistoric population history in eastern Fennoscandia. Journal of Archaeological Science 37(2):251-60. 